\title{
Identification and Characterization of a New Fungal Pathogen Causing Twisted Leaf Disease of Sugarcane in China
}

\begin{abstract}
Zhenyue Lin, Jingjing Wei, and Muqing Zhang, State Key Laboratory for Conservation and Utilization of Subtropical Agro-bioresources, Guanxi University, Nanning, Guanxi 530004, China; and College of Crop Science, Fujian Agriculture and Forestry University, Fuzhou 350002, China; Shiqiang Xu, Qiang Guo, Xin Wang, Jihua Wang, and Baoshan Chen, State Key Laboratory for Conservation and Utilization of Subtropical Agro-bioresources, Guanxi University, Nanning, Guanxi 530004, China; Youxiong Que, Zuhu Deng, and Rukai Chen, College of Crop Science, Fujian Agriculture and Forestry University, Fuzhou 350002, China; Charles A. Powell, IRREC-IFAS, University of Florida, Fort Pierce 34945
\end{abstract}

\begin{abstract}
Lin, Z. Y., Wei, J. J., Zhang, M. Q., Xu, S. Q., Guo, Q., Wang, X., Wang, J. H., Chen, B. S., Que, Y. X., Deng, Z. H., Chen, R. K., and Powell, C. A. 2015. Identification and characterization of a new fungal pathogen causing twisted leaf disease of sugarcane in China. Plant Dis. 99:325-332.

Sugarcane twisted leaf disease, caused by Phoma sp., was first reported in Guangxi, China, in 2012, when more than 5\% of sugarcane was infected in the field. Three single-spore isolates were recovered from symptomatic leaves. Sequences from five fungal loci, 28S nrDNA (LSU), 18S nrDNA (SSU), the internal transcribed spacer regions 1 and 2 and 5.8S nrDNA (ITS), $\beta$-tubulin (TUB), and the translation elongation factor alpha (TEF- $\alpha$ ) were amplified from the disease-associated isolates. The twisted leaf disease pathogen was identified and formally described as Phoma sorghina var. saccharum through phylogenetic analyses, morphological observations, and the pathogenicity of the isolates on sugarcane. P. sorghina var. saccharum can be differenti-

ated from related species based on the morphology of pycnidia and chlamydospores that formed regular, glabrous, papillate ostioles. Chlamydospore-anamorph was unicellular, botryoid-alternarioid shape, as well as the binucleate, frequently branched hyphae. We also showed that mycelial growth of $P$. sorghina var. saccharum was optimal at $\mathrm{pH}$ 4.0 and 20 to $25^{\circ} \mathrm{C}$. Additionally, among 13 chemical compounds tested, carbendazim was found to be the most effective in suppressing the radial growth of the fungus. Mycelial growth in vitro was completely inhibited at concentrations of 100 and $50 \mathrm{ppm}$, and $87.6 \%$ of mycelial growth was inhibited at $10 \mathrm{ppm}$. Carbendazim is therefore a potentially effective fungicide to control this disease in China.
\end{abstract}

Sugarcane is one of the major sources of sugar for human consumption and a leading energy crop worldwide. Guangxi is one of the largest sugarcane production areas in China. During a survey of sugarcane crops conducted in September 2012 and June 2013, approximately 5 to $10 \%$ of the sugarcane crop (cvs. FN-40 and ROC22) planted in Chongzuo and Laibing, Guangxi Zhuang Autonomous Region, China, had twisting and curling symptoms of crown sugarcane leaves similar to sugarcane pokkah boeng disease (caused by Fusarium moniliforme Sheldon). Similar symptoms were also observed in December 2012 at Fuzhou, Fujian, within sugarcane seedling nurseries. The symptoms started appearing as yellowing on midribs and leaf margins, which spread further to the entire leaf, along with twisting and curling of crown leaves. This was the first report of Phoma sp. associated with sugarcane twisted leaf disease by morphological observation and ITS identification in the mainland of China (18).

The genus Phoma is one of the largest fungal genera, with more than 3,000 infrageneric taxa described (22). Approximately 50\% of the Phoma taxa redescribed by Boerema were recognized as relevant phytopathogenic fungi $(2,4)$. Morphological characteristics have been used for the identification of Phoma species, including conidial shape, size, septation, ornamentation, and culture characteristics (11). However, some of these characteristics overlap among species and vary depending on culture conditions such as

Corresponding author: M. Q. Zhang, E-mail: mqzhang@ufl.edu

Z. Y. Lin and J. J. Wei contributed equally to this work.

* The $e$-Xtra logo stands for "electronic extra" and indicates that two supplementary tables are available online.

Accepted for publication 10 September 2014.

http://dx.doi.org/10.1094/PDIS-06-14-0661-RE

(C) 2015 The American Phytopathological Society temperature, $\mathrm{pH}$, and medium (15). To determine the taxonomic distribution of Phoma species, both morphological and molecular phylogenetic analyses are complementary in modern fungal systematics (26). Molecular phylogenetic studies are often conducted using multilocus sequence typing (2). These analyses make use of sequences derived from 28S nrDNA (LSU) (28), 18S nrDNA (SSU) (37), the internal transcribed spacer regions 1 and 2 and $5.8 \mathrm{~S}$ nrDNA (ITS) (37), $\beta$-tubulin (TUB) $(14 ; 38)$, actin (ACT) (6), and the translation elongation factor alpha (TEF- $\alpha)(3)$. In addition, growth characteristics on media, such as growth rate, pigment formation, and colony outline and pattern are also aids for fungal identification (1). Temperature, $\mathrm{pH}$, water activity, and light are considered as the major environmental factors affecting fungal growth and development in plants and culture media (20). However, the taxonomy of the Phoma section is still not fully understood (3).

Species belonging to the genus Phoma and related coelomycetes are often encountered as serious plant pathogens, mostly causing leaf and stem spots. Phoma comprises large taxa whose members appear to be different in their host specificity (38). The host ranges associated with the genus Phoma are diverse, including corn, grain, citrus, and sorghum. Phoma sp. on sugarcane leaves has been reported in India, Pakistan, Hawaii, and China $(12,17,18,31)$. In order to further understand the pathology of sugarcane twisted leaf disease, we identified Phoma sp. from sugarcane isolates by morphological observation, molecular identification, and phylogenetic analyses. We also conducted pathogenicity tests and characterized fungal growth at different temperatures and $\mathrm{pH}$, and tested the fungal responses to chemical compounds in vitro. Our studies lay the groundwork for early identification of Phoma in sugarcane twisted leaf disease and point to strategies for management of this disease.

\section{Materials and Methods}

Fungal cultures and growth. The symptomatic leaves of sugarcane, manifesting twisting and curling, were collected at Nanning 
(E108 ${ }^{\circ} 2^{\prime}, \mathrm{N}^{\circ} 2^{\circ} 88^{\prime}$ ), Guangxi, in September 2012, and Fuzhou $\left(\mathrm{E} 119^{\circ} 23^{\prime}, \mathrm{N} 26^{\circ} 09^{\prime}\right)$, Fujian, China, in January 2013. Leaf tissue $(5 \times 5 \mathrm{~mm})$ was surface-disinfected and cultured, and then single spores were isolated from the growing cultures. Briefly, the tissues were first surface-sterilized by dipping in $70 \%$ ethanol, followed by $30 \mathrm{~s}$ in $0.1 \% \mathrm{HgCl}_{2}$ solution, rinsed three times in sterile water, placed on potato dextrose agar (PDA), and then incubated in darkness at $28^{\circ} \mathrm{C}$. The single conidium-derived isolates were selected from the plates according to a previously described method (16). All cultures were stored at $-80^{\circ} \mathrm{C}$ in the Key Lab of Sugarcane Biology and Genetic Breeding at the Fujian Agriculture and Forestry University, Fuzhou, China.

Morphological observation and pathogenicity test. Microscopic examinations were carried out after 2 weeks of hyphal tip growth on malt extract agar (MEA), oatmeal agar (OA), and PDA plates at $28^{\circ} \mathrm{C}$ in darkness. Sterile water was used as a mounting medium for microscopy. The shape, size, color, opening of ascomata and conidiomata, as well as zone lines were observed under a microscope (ZEISS Scope A1, Carl Zeiss AG, Germany) using standard protocols $(1,2,4)$. One hundred microliters of conidial suspensions $\left(10^{7} \mathrm{CFU} \cdot \mathrm{ml}^{-1}\right)$ of three representative isolates (Fn40, FJ-1, and FJ-2) were micro-injected using a sterile inoculator into 20 seedlings (20 days old) of sugarcane cultivar FN-40. Control seedlings were injected with water without conidia. The inoculated plants were grown in a growth chamber at $28^{\circ} \mathrm{C}$ with a photoperiod of $16 \mathrm{~h}$ light, $8 \mathrm{~h}$ dark.

Effects of temperature and $\mathrm{pH}$ on mycelial growth in vitro. Phoma isolate Fn40 was grown on standard PDA medium $(\mathrm{pH}=$ 5.6) and used for assessing the effect of temperature on radial growth. Temperatures ranged from 5 to $35^{\circ} \mathrm{C}$ at intervals of $5^{\circ} \mathrm{C}$. The $\mathrm{pH}$ effects on the radial growth were investigated on modified PDA medium at different $\mathrm{pH}$ values ranging from 4.0 to 8.0 adjusted by McIlvaine buffers at $25^{\circ} \mathrm{C}$ in darkness $(21,29)$. A 5$\mathrm{mm}$ PDA plug of mycelium of isolate Fn40 was transferred to the center of medium plates for radial growth measurements. For each temperature and $\mathrm{pH}$ tested, four replicate observations were performed. Colony diameter was measured after 7 days of incubation and the isolates were also scored for pigmentation of the mycelia.

Reponses to chemical compounds in vitro. Eight bactericidal or viricidal compounds (rifaximin, lincomycin hydrochloride, cinoxacin, cephalexin 2-methyl-4-isothiazolin-3-one, 2amino-5-chioro-benzoxazole, pasiniazid, and berberine chloride) were purchased from Sigma-Aldrich Co. Ltd (St. Louis, MO). Other registered fungicides were purchased in China, including oxine-copper and emamectin benzoate from Zhejiang Hisen Chemical Co. Ltd. (Zhejiang, China), as well as thiophanate-methyl, mancozeb, and carbendazim from Jiangsu Lanfeng Biochemical Co. Ltd (Jiangsu, China). Different concentrations (100, 50, and 10 ppm) of the chemical compounds were prepared by dissolving the requisite quantity of each compound in warm PDA medium before autoclaving. After autoclaving, the medium was dispensed uniformly into $90-\mathrm{mm}$-diameter petri plates and inoculated with 5-mm mycelial discs of Phoma isolate Fn40. A non-supplemented PDA medium served as a control and each treatment was repeated in triplicate. The plates were incubated at $25^{\circ} \mathrm{C}$ for 3 days in darkness and the diameter of the fungal colony was measured. The inhibitory rate was calculated as follows:

$$
\% \text { inhibition }=\left[\left(\mathrm{G}_{\mathrm{c}}-\mathrm{G}_{\mathrm{t}}\right) / \mathrm{G}_{\mathrm{c}}\right] \times 100
$$

where $G_{c}=$ growth in control and $G_{t}=$ growth in treatment.

All data were analyzed as a generalized linear mixed model using the SAS procedure GLIMMIX. Differences among treatment levels were determined with the LINES option of the LSMEANS statement.

PCR amplification and sequence analysis. DNA from isolates Fn 40, FJ-1, and FJ-2 were extracted with a modified Fungal DNA Midi Kit (Omega Bio-Tek, Inc., USA). DNA derived from TUB, LSU, SSU, ITS, and TEF- $\alpha$ loci were amplified using primers specific for sequences conserved in fungi (Table 1). Each amplification reaction included $25 \mu \mathrm{l}$ of Dream Taq Green PCR Master MIX (Thermo Fisher Scientific, Waltham, MA), $5 \mu \mathrm{l}(10 \mu \mathrm{M})$ of each primer set, and $14 \mu \mathrm{l}$ of $\mathrm{ddH}_{2} \mathrm{O}$ in a final volume of $50 \mu \mathrm{l}$. Conditions for amplification included an initial denaturation at $94^{\circ} \mathrm{C}$ for $5 \mathrm{~min}$, followed by 35 cycles of denaturation $\left(94^{\circ} \mathrm{C}\right.$ for 30 s), annealing (48 to $57^{\circ} \mathrm{C}$ for 1 min depending on the locus), and extension $\left(72^{\circ} \mathrm{C}\right.$ for $\left.3 \mathrm{~min}\right)$. A final extension was conducted at $72^{\circ} \mathrm{C}$ for $10 \mathrm{~min}$. Annealing temperatures were $48^{\circ} \mathrm{C}$ for LSU and SSU, $56^{\circ} \mathrm{C}$ for ITS and TUB, and $57^{\circ} \mathrm{C}$ for TEF- $\alpha$, respectively. All PCR reactions were performed on a Gene Amp PCR System 9700 (Applied Biosystems, Foster City, CA). Amplified products were sequenced by Sangon BiotechCo., Ltd (Shanghai, China).

Phylogenetic analyses. TUB, LSU, SSU, ITS, and TEF- $\alpha$ locus sequence data from the three isolates as well as reference sequences obtained from CBS or NCBI are summarized in Supplementary Table 1 (2) and Supplementary Table 2 (3), respectively. Sequences were first analyzed using DNAMAN version 4.0 (DNAMAN, Lynnon Biosoft, San Ramon, CA). All sequences derived from different loci in each isolate were concatenated for a single nucleotide alignment. Nucleotide sequences were aligned using CLUSTAL W implemented in MEGA 6.0 followed by manual modification, and gaps were coded as missing data $(23,35)$. Phylogenetic trees were generated using maximum likelihood analysis with the Kimura 2 parameter method on the concatenated alignments. Statistical significance of the tree branches was assessed using 1,000 bootstrap replications $(13,33)$. Phylograms with the representative bootstrap values ( $\geq 50 \%)$ above each branch were generated using the tree explorer available in MEGA 6.0 (34).

\section{Results}

Species identification within the genus Phoma. Molecular phylogenetic analysis. Amplified PCR products were 380 bp (TUB locus), 1,350 bp (LSU), 1,070 bp (SSU), 540 bp (ITS), and 930 bp (TEF- $\alpha$ ), respectively. The sequences obtained from the three isolates (Fn40, FJ-1, and FJ-2) were deposited in GenBank. In order to accurately identify the disease-associated fungal isolates, a phylogenetic tree for the Phoma species complex was constructed using the maximum likelihood method. Input for this analysis was based on the LSU+ITS+SSU+TEF- $\alpha$ loci of the disease-associated isolates and other reference sequences. Nine clades were revealed in the combined phylogenetic tree based on the LSU-ITS-SSUTEF- $\alpha$ phylogeny, when the tree was rooted to Pseudorobillarda

Table 1. Primers used for the identification of Phoma sorghina var. saccharum

\begin{tabular}{|c|c|c|c|}
\hline$\underline{\text { Locus }}$ & Primer & Primer sequence $5^{\prime}-3^{\prime}$ & References \\
\hline \multirow[t]{2}{*}{ TUB } & TUB2Fd & GTBCACCTYCARACCGGYCARTG & Groenewald et al. (14); \\
\hline & TUB4Rd & CCRGAYTGRCCRAARACRAAGTTGTC & Woudenberg et al. (38) \\
\hline \multirow[t]{2}{*}{ ITS } & ITS1 & TCCGTAGGTGAACCTGCGG & White et al. (37) \\
\hline & ITS4 & TCCTCCGCTTATTGATATGC & \\
\hline \multirow[t]{2}{*}{ LSU } & LR0R & GTACCCGCTGAACTTAAGC & Rehner and Samuels (28); \\
\hline & LR7 & TACTACCACCAAGATCT & Vilgalys and Hester (36) \\
\hline \multirow[t]{2}{*}{ SSU } & NS1 & GTAGTCATATGCTTGTCTC & White et al. (37) \\
\hline & NS4 & CTTCCGTCAATTCCTTTAA & \\
\hline \multirow[t]{2}{*}{ TEF- $\alpha$} & Efdf & AAGGAYGGNCARACYCGNGARCAYGC & www.aftol.org/pdfs/EF1primer.pdf \\
\hline & EF1-2218R & ATGACACCRACRGCRACRGTYTG & \\
\hline
\end{tabular}


phragmitis (CBS 398.61) as an outgroup specimen (Fig. 1). These findings were largely in congruence with the observations of Aveskamp et al. (2). Ten previously described species in the genus Phoma as well as our disease-associated isolates (Fn40, FJ-1, and FJ-2) formed a monophyletic clade in Didymellaceae with $99 \%$ bootstrap support, indicating that our three isolates were closely related to Chaetasbolisia erysiphoides (CBS 148.94) and Epicoccum nigrum (CBS 173.73) in the clade Didymellaceae. The phylogenetic tree clearly showed that the disease-associated fungus was a species of the genus Phoma (Fig. 1).

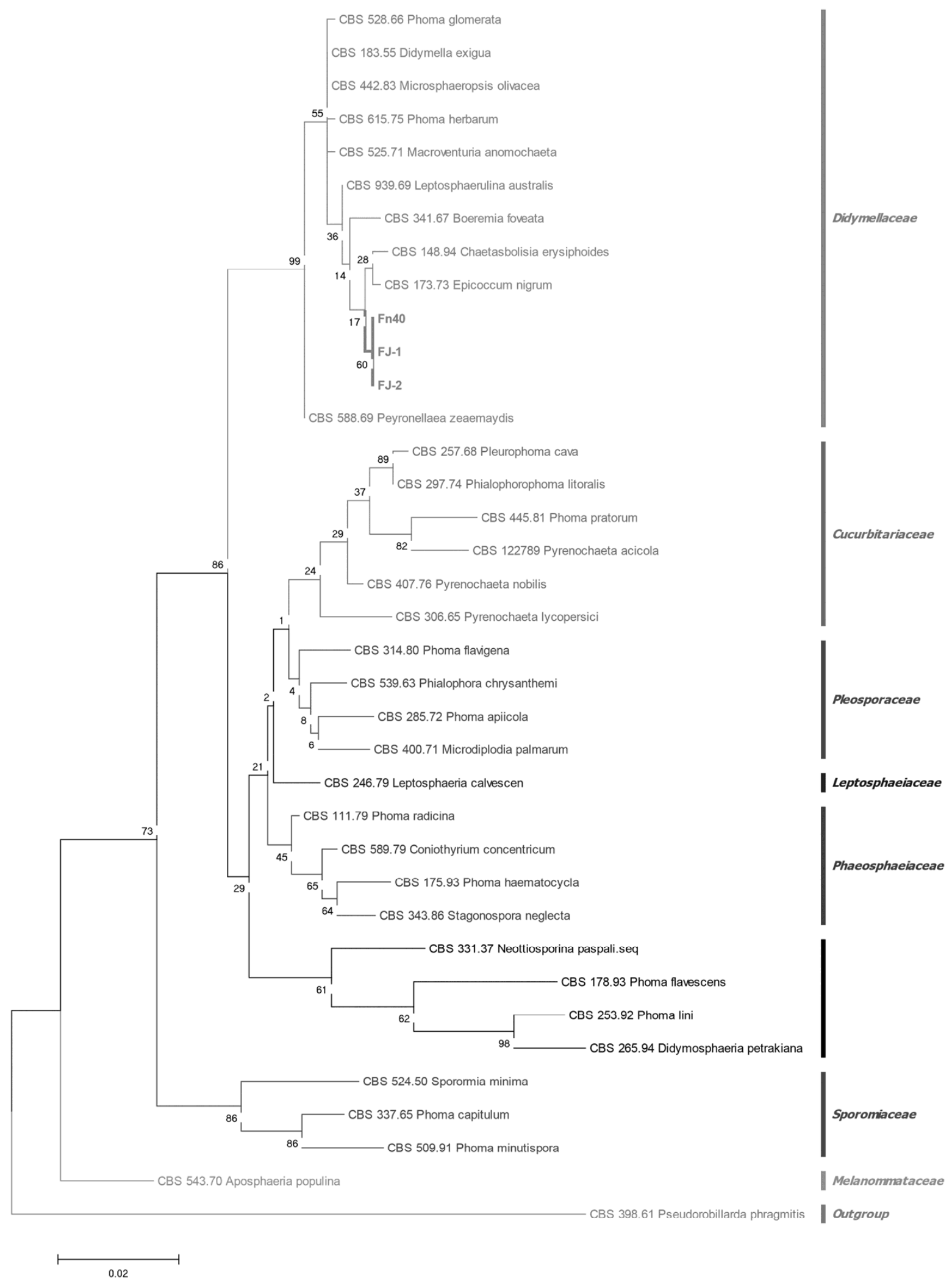

Fig. 1. Phylogenetic tree constructed using the maximum likelihood method and inferred from the combined four locus, LSU-ITS-SSU-TEF-a, taxon data set rooted with sequences derived from Pseudorobillarda phragmitis (CBS 398.61). Bootstrap values $\geq 50 \%$ from 1,000 replicates of the data are indicated above nodes. The positions of the $\mathrm{Fn40,FJ-1,} \mathrm{and} \mathrm{FJ-2} \mathrm{isolates} \mathrm{are} \mathrm{indicated} \mathrm{in} \mathrm{bold} \mathrm{text.}$ 


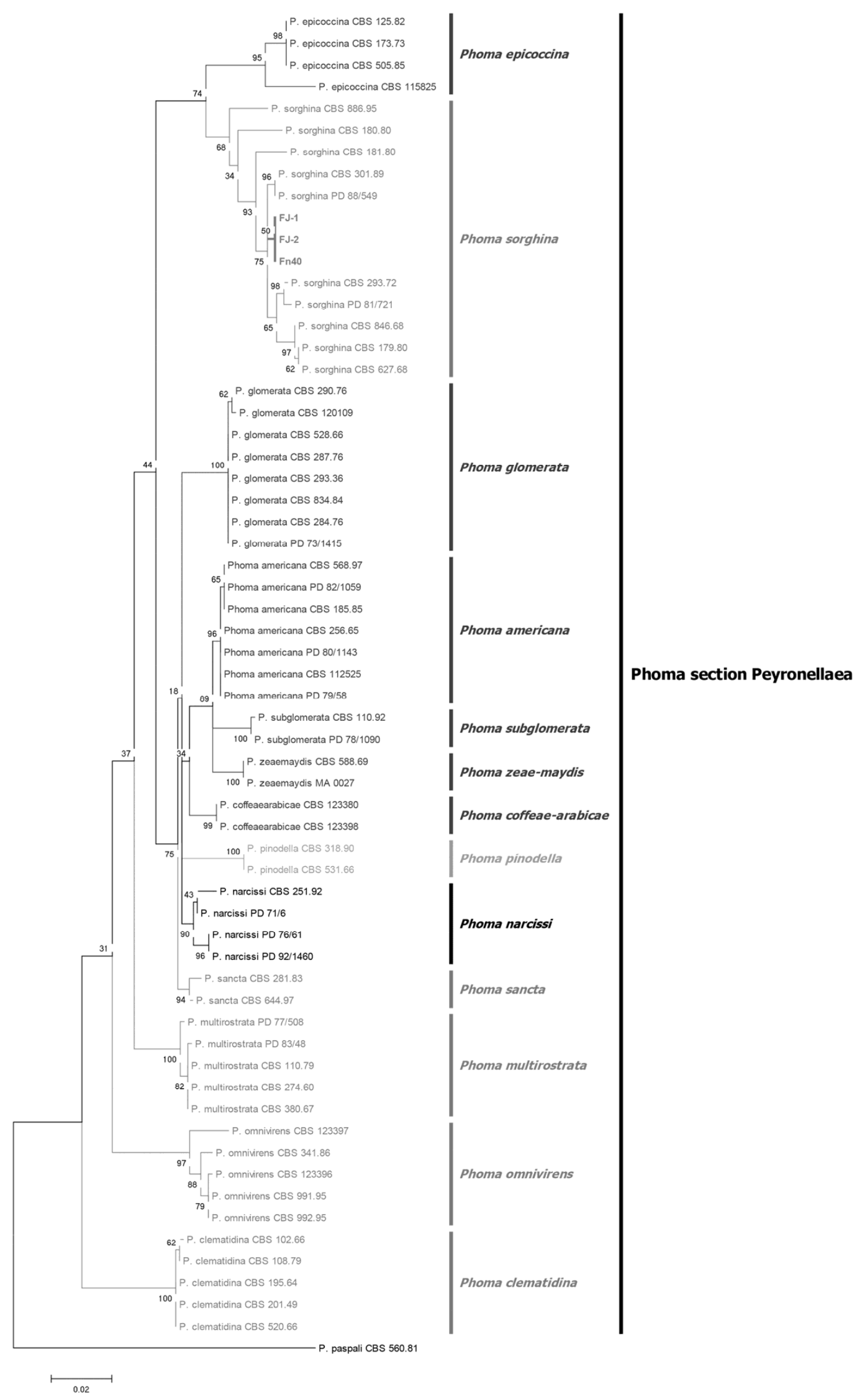

Fig. 2. Phylogenetic tree constructed using the maximum likelihood method and inferred from the combined LSU-ITS-TUB sequences. The taxon data set was rooted with sequences derived from P. paspali (CBS 560.81). Bootstrap values $\geq 50 \%$ from 1,000 replicates of the data are indicated above nodes. The positions of the Fn40, FJ-1, and FJ-2 isolates are indicated in bold text. 
To further assess evolutionary relationships of the disease-associated Phoma isolates within the Didymellaceae clade, the nucleotide sequences derived from LSU, ITS, and TUB loci were aligned for 59 taxa in the Peyronellaea section of Phoma, including one outgroup taxon (CBS 560.81 P. paspali). Maximum likelihood analysis was used to construct a second phylogenetic tree of these Phoma species. The synonymy on the Phoma species was referred to in Aveskamp et al. (3). Ten isolates of $P$. sorghina and our Phoma isolates (Fn40, FJ-1, and FJ-2) formed a monophyletic group, indicating that our Phoma isolates were ascribed to P. sorghina (Fig. 2). The results presented here revealed little genetic variation within isolates of $P$. sorghina from Lycopersicon esculentum (CBS 301.89), Sorghum vulgare (CBS 179.80), Zea mays (CBS 180.80), and Citrus sp. (CBS 627.68) (3).

Morphological observations. The pycnidia of isolates produced on the agar surface were regular glabrous, solitary or confluent, globose to subglobose, 50 to $200 \times 75$ to $250 \mu \mathrm{m}$, with papillate ostioles, brown/brown-black (Fig. 3I). The pycnidial wall was pseudoparenchymatous and composed of oblong to isodiametric cells in one layer (Fig. 3H). Conidiogenous cells were phialidic, hyaline, simple, smooth, fusiform, and relatively small, approx. 3.5 to $5 \times 3$ to $4 \mu \mathrm{m}$ (Fig. 3G). Conidia were ellipsoidal to cylindrical, thin-walled, smooth, hyaline, and aseptate, 3 to $5 \times 1.5$ to $3 \mu \mathrm{m}$, with a creamy white matrix. Chlamydospores with a diameter of 5 to $10 \mu \mathrm{m}$ were dark brown or olivaceous, terminal on erect aerial hyphae, and solitary. A single chlamydospore was below the colony, with a reddish or yellowish discoloration. Chlamydosporeanamorph was unicellular, botryoid-alternarioid shape (Fig. 3E). Hyphae were thick-walled, septate, binucleate, and hyaline (Fig. 3D). The mycelia were thick and septate. Conidiophores formed from buds on the hyphae and were unbranched to rarely branched, straight or flexuous, globose, pale brown to medium brown, smooth, 10 to $20 \times 10$ to $15 \mu \mathrm{m}$ in size, and had 1 to 2 percurrent proliferations (Fig. 3F).

Culture characteristics. Colonies on OA medium had irregular margins and were 50 to $60 \mathrm{~mm}$ in diameter after 7 days of incuba-

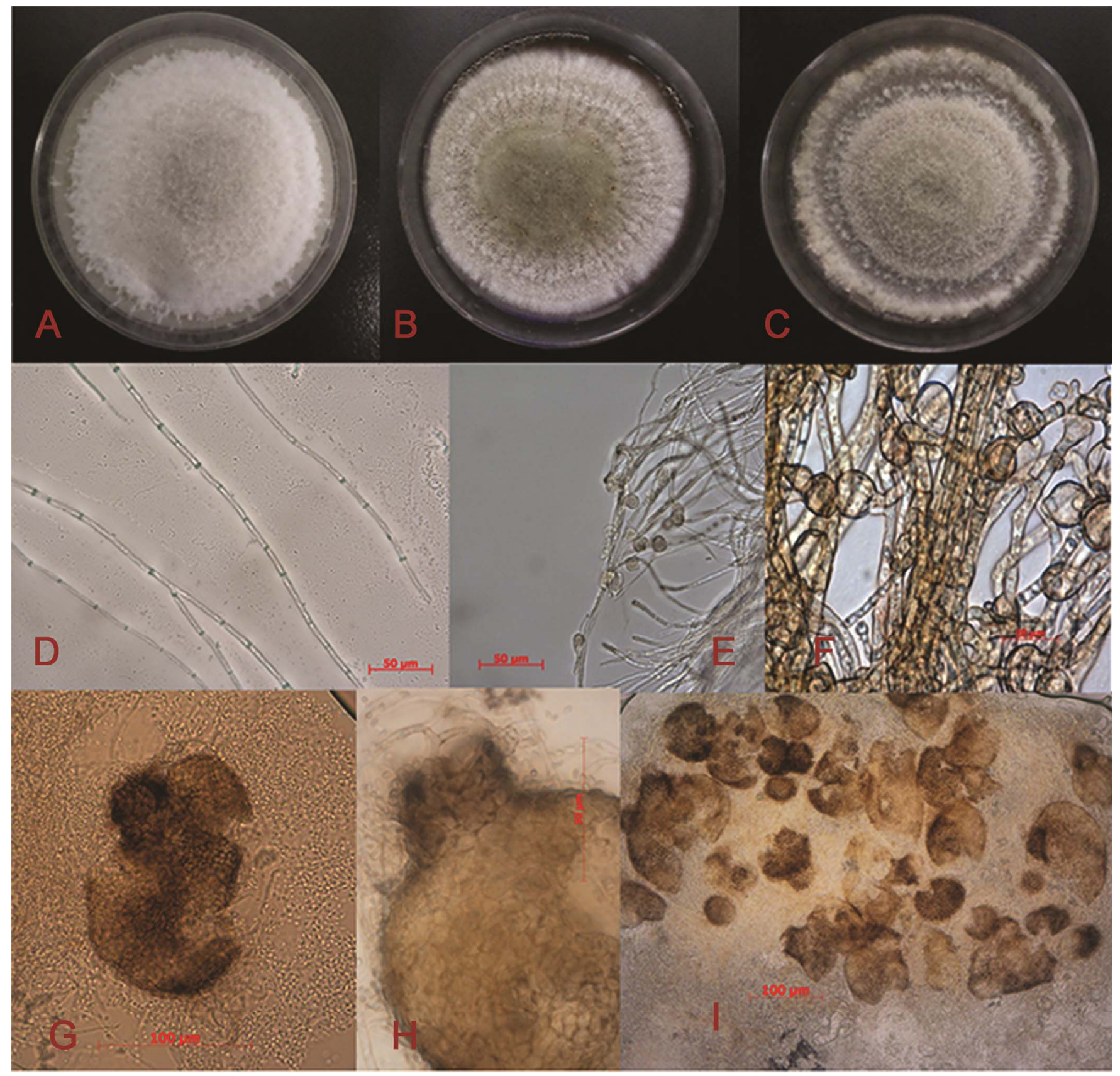

Fig. 3. Morphological observation of Phoma sorghina var. saccharum. A-C, Seven-day-old colonies on OA (A), MEA (B), and PDA (C). D, Septate hyphae. E, Chlamydospore. F, Asexual conidia formation. G-I, Pycnidia and conidiophores. 
tion. Immersed mycelia were rarely visible due to the aerial mycelia. Mycelia were hyaline or white with many pycnidia from the top, while it was grayish to olivaceous-buff at the bottom (Fig. 3A). Colonies on MEA medium had regular margins and were 45 to $55 \mathrm{~mm}$ in diameter after being cultured for 7 days. Immersed mycelia were hyaline or amber. Only the sparsely small white tufts of aerial mycelia were produced in the older cultures from the top, while it was black at the bottom (Fig. 3B). Colonies on PDA had regular margins and were 45 to $55 \mathrm{~mm}$ in diameter after being cultured for 7 days. Immersed mycelia were hyaline and white, and the colonies appeared as white, villous, spherical, radial, and densely packed colorless mycelia from the top, while it was reddish-brown at the bottom and later changed to a grayish color (Fig. 3C).

As characterized by Boerema et al. (4) and Aveskamp et al. (2), $P$. sorghina occasionally produced micropycnidia that developed from a hyphal cell or from a single chlamydospore cell. Chlamydospore-anamorph was unicellular or multicellular, botryoid-alternarioid shape. However, the various strains of Phoma section Peyronellaea, including $P$. sorghina, showed extreme variability in the shape and size of the chlamydospore (4). In our current study, fungal isolates had a unique characteristic, whereby the produced chlamydospores were botryoid or epicoccoid with a diameter of 5 to $10 \mu \mathrm{m}$. These chlamydospores were unicellular with dark brown or olivaceous pigmentation, terminal on erect aerial hyphae, and individual with papillate of pycnidia and conidia aseptate. Through studies of phylogenetic analysis together with morphological observations, we formally describe our isolates as $P$. sorghina var. saccharum (MycoBank: MB808056) based on the genus of the host plant (Saccharum officinarum L.).

Pathogenicity test of $P$. sorghina var. saccharum from China. Twisted and curly leaf symptoms similar to those observations of sugarcane plants growing in the field appeared on the inoculated sugarcane leaves at 10 days after inoculation. The symptoms started as yellowing on midribs and leaf margins that spread fur- ther to the entire leaf, along with twisting and curling of crown leaves (Fig. 4A, 4B). Uninoculated control leaves remained asymptomatic (Fig. 4C). The pathogens that were inoculated onto the sugarcane seedlings were reisolated from representative lesions and their identity confirmed, completing Koch's postulates. The Phoma sp. pathogen associated with sugarcane leaf twisting disease was formally described herein as $P$. sorghina var. saccharum.

Effects of temperature and pH on mycelial growth in vitro. Results of variance analysis showed a significant effect of temperature $(P<0.0001)$ on the mycelial growth of fungal isolate Fn40. Isolate Fn40 grew most slowly at 5 and $35^{\circ} \mathrm{C}$ and the optimum temperature ranged from 20 to $25^{\circ} \mathrm{C}$ (Fig. 5A). For all tested $\mathrm{pH}$ values, $\mathrm{pH} 4.0$ was optimum for the mycelial growth of $P$. sorghina var. saccharum (Fig. 5B).

Reponses of $P$. sorghina var. saccharum to chemical compounds in vitro. Thirteen compounds were tested at three concentrations $(100,50$, and $10 \mathrm{ppm})$ for their ability to inhibit mycelial growth of P. sorghina var. saccharum (Fig. 6). Among the tested compounds, carbendazim was the most effective in inhibiting the radial growth. Mycelial growth was completely inhibited at 100 and $50 \mathrm{ppm}$, and $87.6 \%$ of mycelial growth was inhibited at 10 ppm. Three compounds including mancozeb, carbendazim, and copper 8-hydroxyquinoline inhibited mycelial growth by more than $50 \%$ at all tested concentrations. Six antibacterial compounds (rifaximin, lincomycin hydrochloride, cinoxacin, cephalexin, berberine chloride, and emamectin benzoate) and one antiviral compound (pasiniazid) had no effect on the mycelial growth of $P$. sorghina var. saccharum. Two fungicides, including 2-amino-5chioro-benzoxazole and thiophanate-methyl, partially inhibited mycelial growth only at the concentration of 100 ppm (Fig. 6).

\section{Discussion}

Species within the coelomycete genus Phoma are ubiquitous in the environment and occupy numerous ecological niches (1).

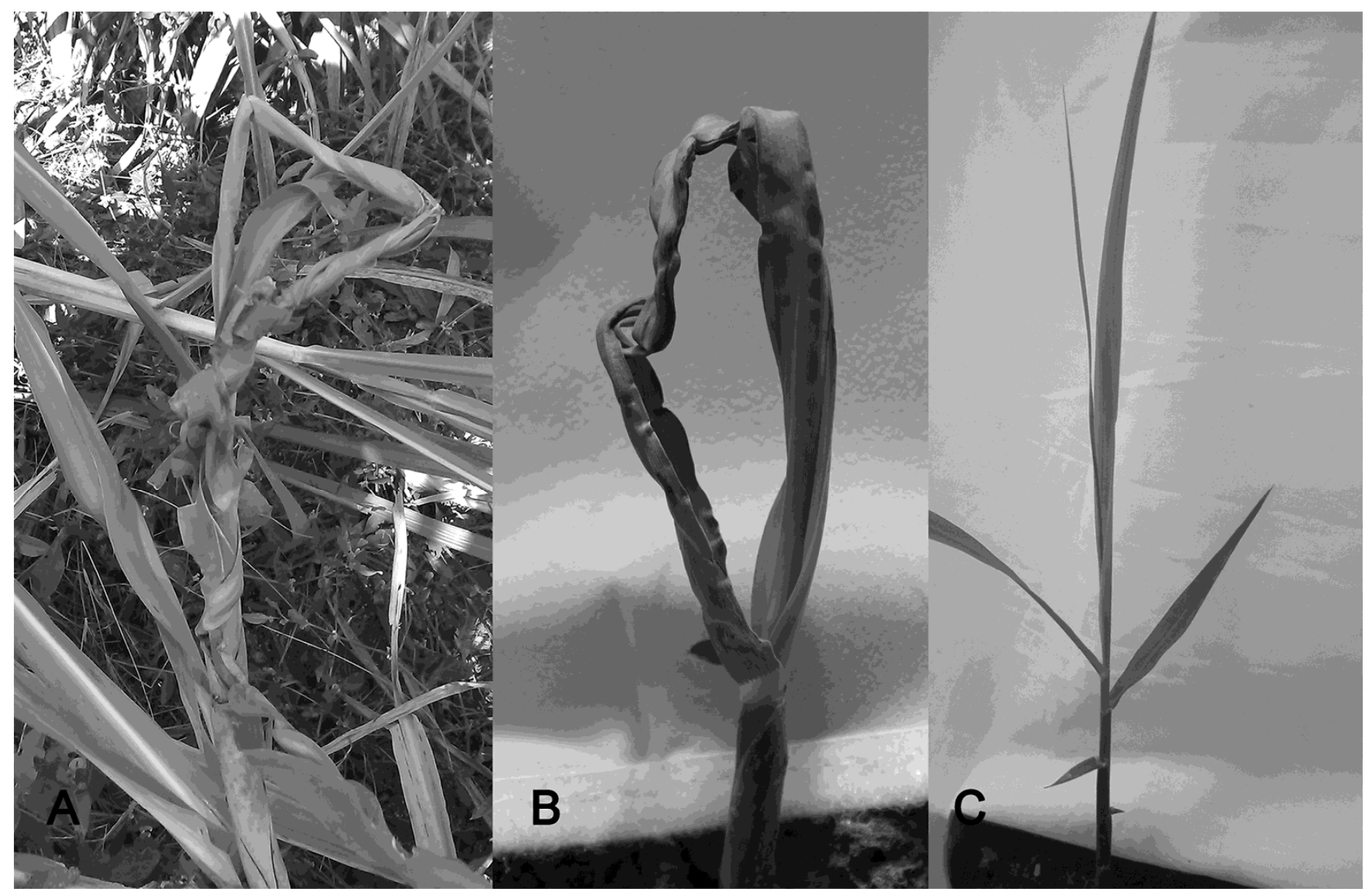

Fig. 4. Twisted and curly symptoms of sugarcane (cultivar FN40) leaves in the field (A) and on plants inoculated with Phoma sorghina var. saccharum (B). No symptoms were observed on the healthy control plants inoculated with water (C). 
Phoma is an important pathogen of many plants and crops, and causes significant yield losses. In Australia in the 1970s, rapeseed yield was drastically reduced by epidemics of blackleg caused by Phoma lingam (anamorph) (30). Sugarcane twisted leaf disease, caused by Phoma sp., was first reported in Guangxi, China, in 2012 (18). On the basis of disease incidence and severity observed in several regions in China, we believe that this disease may pose a serious threat to cane production and management in the future. $P$. sorghina on sugarcane leaves or sugarcane disease caused by Phoma sp. has been reported in Pakistan, Hawaii, and Taiwan $(12,17,31)$. According to our morphological observations, molecular phylogenetic trees, and culturing experiments, we formally described and established our disease-associated isolates as $P$. sorghina var. saccharum. The isolates described here were pathogenic on inoculated sugarcane, and produced identical symptoms to those observed in the field, thus confirming their role as the causal agent of twisted leaf disease of sugarcane in China. To the best of our knowledge, it is the first report to identify the pathogen causing this disease.

Based on detailed studies of its morphology, P. sorghina var. saccharum can be differentiated from other known species of Phoma by the morphology of the pycnidia and chlamydospores. The chlamydospores of $P$. sorghina var. saccharum were unicellular, botryoid or epicoccoid, terminal on erect aerial hyphae, and individual with papillate of pycnidia and conidia aseptate. Species linked to Phoma section Peyronellaea are typified as chlamydospore-producing, which is a useful characteristic to use for taxon delineation (3). However, the various strains of Peyronellaea show extreme variability in the shape and size of the chlamydospores (4). In addition, the reddish tint of the culture may serve as an additional distinguishing morphological feature for this species.

The availability of DNA sequence data at multiple loci led to major developments in systematics and the ability to correctly identify coelomycetous fungi (5). Phylogenetic studies based on
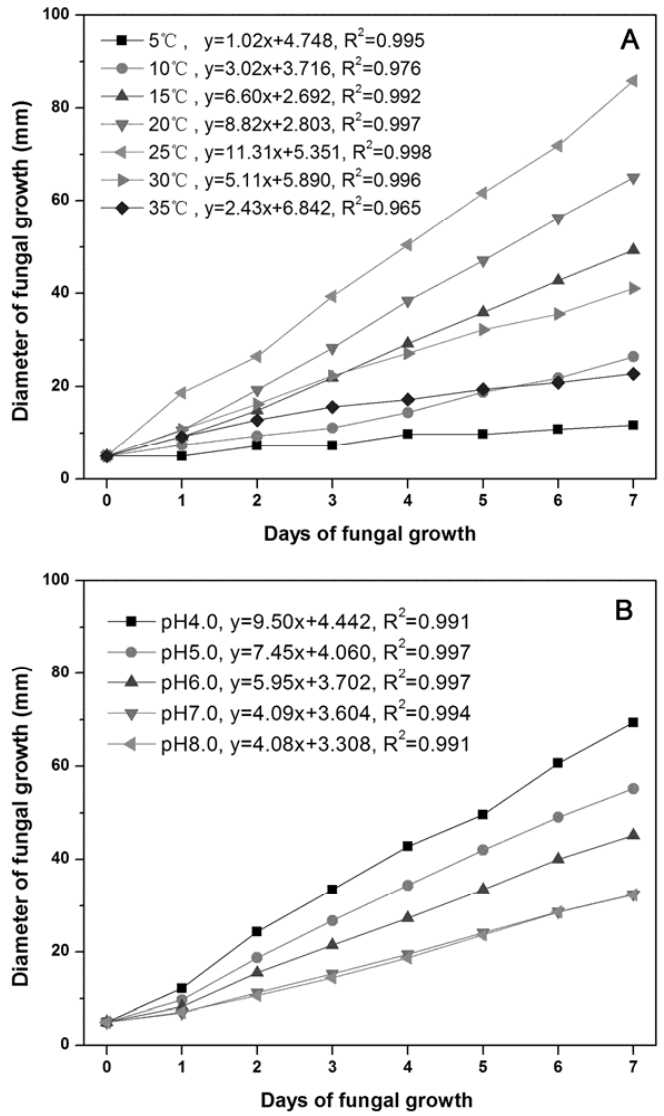

Fig. 5. Radial growth of $P$. sorghina var. saccharum in response to different temperatures $(\mathbf{A})$ and $\mathrm{pH}(\mathrm{B})$ on standard PDA medium.
LSU+ITS+SSU+TEF- $\alpha$ loci were conducted for the Phoma species complex as described by Aveskamp (2). When our isolates (FN40, $\mathrm{FJ} 1$, and FJ2) were included in this analysis, results showed that $P$. sorghina var. saccharum is classified in the Didymellaceae clade. The Didymellaceae clade is one of the major clusters observed in the genetic phylogeny, such that five out of nine Phoma sections are related to the Didymellaceae (9). Furthermore, the results obtained from a phylogenetic tree based on LSU+ITS+TUB loci for the Phoma section Peyronellaea were consistent with a previous report by Aveskamp (3). P. sorghina var. saccharum was grouped with other $P$. sorghina species, but the host ranges associated with $P$. sorghina revealed little genetic variation (25). The position of $P$. sorghina relative to $P$. epicoccum was of particular interest because $P$. sorghina was closely related to $P$. epicoccum (2). P. epicoccum occurs in a wide variety of plants, soil, and other substrates (4). It is also encountered as a facultative plant pathogenic fungus with a preference for Gramineae in tropical regions, and causes leaf spot (25). P. sorghina var. saccharum causes symptoms of twisting and curling on crown leaves of sugarcane, and this specialization is a new characteristic.

Environmental factors, such as temperature and $\mathrm{pH}$, are key factors that influence the growth and development of disease-associated fungal mycelia in plants. We observed in vitro growth of $P$. sorghina var. saccharum mycelia under a wide range of temperatures $\left(5\right.$ to $\left.35^{\circ} \mathrm{C}\right)$. The optimum temperature for mycelial growth was between 20 and $25^{\circ} \mathrm{C}$. These findings were in agreement with those observed for $P$. macdonaldii and P. lingam (29), indicating that $P$. sorghina var. saccharum has a preference for growth in subtropical climates. The radial growth rate of the mycelium decreased at temperatures above $30^{\circ} \mathrm{C}$.

Most phytopathogenic fungi grow optimally in a $\mathrm{pH}$ range between 5 and 6.5 (8). However, P. sorghina var. saccharum exhibited growth typical of a fungus specialized for acidic habitats. The isolate of $P$. sorghina var. saccharum exhibited optimal growth at $\mathrm{pH}$ 4. Preference for acidic conditions was also reported for Acidomyces acidophilus (32). However, P. sorghina var. saccharum had a lower growth rate at $\mathrm{pH} 7.0$ and 8.0 (Fig. 5B). Our results could be important for future studies aiming to control the incidence of $P$. sorghina var. saccharum in the field.

Fungicides are especially valuable because their toxicity to nontarget animals and humans is lower (10). Effective chemical control of sugarcane fungal diseases caused by $P$. sorghina var. saccharum requires appropriate information on the sensitivity of this fungus to a range of fungicidal compounds. Although it is difficult to correlate the effects of fungicides in vitro with their performance in the field, such studies must serve as the first step for designing strategies for disease control (24). A total of 13 chemical com-

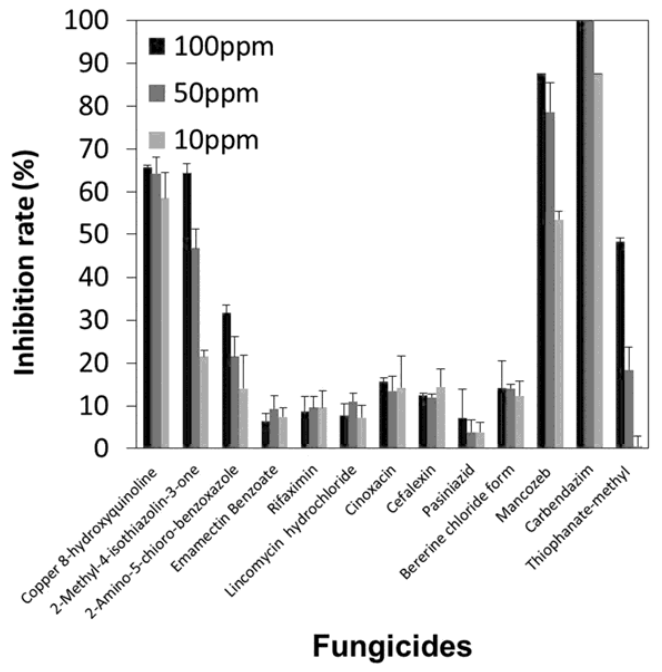

Fig. 6. Inhibition rate (\%) of fungicides on Phoma sorghina var. saccharum in vitro. Data are presented as the mean of three independent experiments \pm SD. 
pounds, including some commonly used fungicides, were used to evaluate their ability to inhibit the growth of $P$. sorghina var. saccharum mycelia in vitro. The strongest inhibition of mycelial growth was observed in cells treated with carbendazim followed by mancozeb. Of the other fungicides tested, copper 8-hydroxyquinoline, 2-methyl-4-isothiazolin-3-one, 2-amino-5-chioro-benzoxazole, and thiophanate-methyl were moderately to highly inhibitory of fungal growth. However, six antibacterial compounds and one antiviral compound were not effective against mycelial growth of P. sorghina var. saccharum. Benzimidazoles, particularly carbendazim, are site-specific fungicides that interfere with cell division (7), and comprise a well-known group of $\beta$-tubulin disruptors that affect micro-tubule function in many fungi $(19,27)$. In our study, mycelial growth was inhibited by low concentrations of carbendazim, which might decrease the virulence of this pathogen in nature. Therefore, carbendazim is a potentially useful fungicide against $P$. sorghina var. saccharum, the causal agent of sugarcane twisted leaf disease, and may be effective in managing the disease in China and preventing its spread. The findings of this study will provide basic information for $P$. sorghina var. saccharum management in the field.

\section{Acknowledgments}

The authors are grateful to Bioscience Editing Solutions for critically reading this paper and providing helpful suggestions. Financial support was provided by Guangxi natural science foundation (project 2014GXNSFFA118002), Guangxi special funding for distinguished experts, and Funds from State Key Laboratory for Conservation and Utilization of Subtropical Agro-bioresources.

\section{Literature Cited}

1. Aveskamp, M., De Gruyter, J., and Crous, P. 2008. Biology and recent developments in the systematics of Phoma, a complex genus of major quarantine significance. Fungal Divers. 31:1-18.

2. Aveskamp, M., De Gruyter, J., Woudenberg, J., Verkley, G., and Crous, P. W. 2010. Highlights of the Didymellaceae: A polyphasic approach to characterise Phoma and related pleosporalean genera. Stud. Mycol. 65:1-60.

3. Aveskamp, M. M., Verkley, G. J., de Gruyter, J., Murace, M. A., Perello, A., Woudenberg, J. H., Groenewald, J. Z., and Crous, P. W. 2009. DNA phylogeny reveals polyphyly of Phoma section Peyronellaea and multiple taxonomic novelties. Mycologia 101:363-382.

4. Boerema, G., De Gruyter, J., Noordeloos, M., and Hamers, M. E. 2004. Phoma sect. Plenodomus. Pages 364-366 in: Phoma identification manual. CABI Publishing, Wallingford, UK.

5. Bridge, P. 2002. The history and application of molecular mycology. Mycologist 16:90-99.

6. Carbone, I., and Kohn, L. M. 1999. A method for designing primer sets for speciation studies in filamentous ascomycetes. Mycologia 91:553-556.

7. Chen, Y., and Zhou, M. G. 2009. Characterization of Fusarium graminearum isolates resistant to both carbendazim and a new fungicide JS399-19. Phytopathology 99:441-446.

8. Cochrane, V. W. 1958. Physiology of fungi. John Wiley \& Sons, New York.

9. De Gruyter, J., Aveskamp, M. M., Woudenberg, J. H., Verkley, G. J., Groenewald, J. Z., and Crous, P. W. 2009. Molecular phylogeny of Phoma and allied anamorph genera: Towards a reclassification of the Phoma complex. Mycol. Res. 113:508-519.

10. Demirci, F., Muştu, M., Kaydan, M. B., and Ülgentürk, S. 2011. Effects of some fungicides on Isaria farinosa, and in vitro growth and infection rate on Planococcus citri. Phytoparasitica 39:353-360.

11. Deng, J. X., Paul, N. C., Li, M. J., Cho, H. S., Lee, H. B., and Yu, S. H. 2013. Stemphylium platycodontis sp. nov., isolated from Platycodon grandiflorus in Korea. Mycol. Prog. Online publication. doi: 10.1007/ s11557-013-0929-z

12. Eriksson, O. E., and Hawksworth, D. L. 2003. Saccharicola, a new genus for two Leptosphaeria species on sugar cane. Mycologia 95:426-433.

13. Felsenstein, J. 1985. Confidence limits on phylogenies: an approach using the bootstrap. Evolution 39:783-791.

14. Groenewald, J., Nakashima, C., Nishikawa, J., Shin, H.-D., Park, J. H., Jama, A. N., Groenewald, M., Braun, U., and Crous, P. W. 2013. Species concepts in Cercospora: spotting the weeds among the roses. Stud. Mycol.
75:115-170.

15. Hosen, M., Ahmed, A., Zaman, J., Ghosh, S., and Hossain, K. 2009. Cultural and physiological variation between isolates of Stemphylium botryosum the causal of Stemphylium blight disease of lentil (Lens culinaris). World J. Agric. Sci. 5:94-98.

16. Ho, W. C., and Ko, W. H. 1997. A simple method for obtaining single-spore isolates of fungi. Bot. Bull. Acad. Sin. 38:41-44.

17. Hsien, W.-H. 1980. Important leaf diseases brown spot, rust and leaf blight of sugarcane in Taiwan. Pages 20-26 in: Proc. S. Asian Symp. Plant Dis. Trop., Bangkok.

18. Lin, Z., Que, Y., Deng, Z., Xu, S., Rao, G. P., and Zhang, M. 2014. First report of Phoma sp. causing twisting and curling of crown leaves of sugarcane in mainland of China. Plant Dis. 98:850.

19. Liu, N., Fan, F., Qiu, D., and Jiang, L. 2013. The transcription cofactor FgSwi6 plays a role in growth and development, carbendazim sensitivity, cellulose utilization, lithium tolerance, deoxynivalenol production and virulence in the filamentous fungus Fusarium graminearum. Fungal Genet. Biol. 58:42-52.

20. Maurice, S., Coroller, L., Debaets, S., Vasseur, V., Le Floch, G., and Barbier, G. 2011. Modelling the effect of temperature, water activity and $\mathrm{pH}$ on the growth of Serpula lacrymans. J. Appl. Microbiol. 111:1436-1446.

21. McIlvaine, T. C. 1921. A buffer solution for colorimetric comparison. J. Biol Chem. 49:183-186.

22. Montel, E., Bridge, P., and Sutton, B. 1991. An integrated approach to Phoma systematics. Mycopathologia 115:89-103.

23. Nei, M., and Kumar, S. 2000. Molecular evolution and phylogenetics. Oxford University Press.

24. Pappas, A. 1997. Evolution of fungicide resistance in Botrytis cinerea in protected crops in Greece. Crop Prot. 16:257-263.

25. Pažoutová, S. 2009. Genetic variation of Phoma sorghina isolates from Southern Africa and Texas. Folia Microbiol. 54:217-229.

26. Pei, Y. F., Wang, Y., Geng, Y., O’Neill, N. R., and Zhang, X. G. 2011. Three novel species of Stemphylium from Sinkiang, China: their morphological and molecular characterization. Mycol. Prog. 10:163-173.

27. Qiu, J., Huang, T., Xu, J., Bi, C., Chen, C., and Zhou, M. 2012. $\beta$-Tubulins in Gibberella zeae: their characterization and contribution to carbendazim resistance. Pest Manag. Sci. 68:1191-1198.

28. Rehner, S. A., and Samuels, G. J. 1994. Taxonomy and phylogeny of Gliocladium analysed from nuclear large subunit ribosomal DNA sequences. Mycol. Res. 98:625-634.

29. Roustaee, A, Costes, S, Dechamp-Guillaume, G, and Barrault, G. 2000. Phenotypic variability of Leptosphaeria lindquistii (anamorph: Phoma macdonaldii), a fungal pathogen of sunflower. Plant Pathol. 49:227-234.

30. Salisbury, P. A., Ballinger, D. J., Wratten, N., Plummer, K. M., and Howlett, B. J. 1995. Blackleg disease on oilseed Brassica in Australia: a review. Austral. J. Exp. Agr. Animal Husb. 35:665-672.

31. Sanguino, A., and Tokeshi, H. 1980. Fungus pathology in sugarcane caryopses. Proc. Int. Soc. Sugar Cane Technol. 17:1563-1568.

32. Selbmann, L., De Hoog, G., Zucconi, L., Isola, D., Ruisi, S., van den Ende, A. H., Ruibal, C., De Leo, F., Urzì, C., and Onofri, S. 2008. Drought meets acid: three new genera in a dothidealean clade of extremotolerant fungi. Stud. Mycol. 61:1-20.

33. Tamura, K., Dudley, J., Nei, M., and Kumar, S. 2007. MEGA4: molecular evolutionary genetics analysis (MEGA) software version 4.0. Mol. Biol. Evol. 24:1596-1599.

34. Tamura, K., Peterson, D., Peterson, N., Stecher, G., Nei, M., and Kumar, S. 2011. MEGA5: molecular evolutionary genetics analysis using maximum likelihood, evolutionary distance, and maximum parsimony methods. Mol. Biol. Evol. 28:2731-2739.

35. Thompson, J. D., Higgins, D. G., and Gibson, T. J. 1994. CLUSTAL W: improving the sensitivity of progressive multiple sequence alignment through sequence weighting, position-specific gap penalties and weight matrix choice. Nucleic Acids Res. 22:4673-4680.

36. Vilgalys, R., and Hester, M. 1990. Rapid genetic identification and mapping of enzymatically amplified ribosomal DNA from several Cryptococcus species. J. Bacteriol. 172:4238-4246.

37. White, T. J., Bruns, T., Lee, S., and Taylor, J. 1990. Amplification and direct sequencing of fungal ribosomal RNA genes for phylogenetics. Pages 315322 in: PCR protocols: a guide to methods and applications. Academic Press, New York.

38. Woudenberg, J., Aveskamp, M., De Gruyter, J., Spiers, A., and Crous, P. 2009. Multiple Didymella teleomorphs are linked to the Phoma clematidina morphotype. Persoonia 22:56-62. 